\section{JURNAL EKONOMI EFEKTIF}

ISSN : $2622-8882$, E-ISSN : 2622-9935

Jurnal Ekonomi Efektif, Vol. 3, No. 1, Oktober 2020 @Prodi Manajemen Fakultas Ekonomi Universitas Pamulang

\title{
PENGARUH MODAL KERJA TERHADAP PROFITABILITAS PADA PT. JAPFA COMFEED INDONESIA. TBK PERIODE TAHUN 2010-2019
}

\author{
Asep Muhammad Lutfi ${ }^{1 *}$, Ria Rosalia Simangunsong ${ }^{2}$, Yusni Nuryani ${ }^{3}$ \\ Universitas Pamulang \\ dosen02469@unpam.ac.id*
}

\begin{abstract}
ABSTRAK
Penelitian ini bertujuan untuk mengetahui pengaruh modal kerja terhadap profitabilitas pada PT. Japfa Comfeed Indonesia. Tbk. Metode yang digunakan adalah explanatory research. Teknik analisis menggunakan analisis statistik dengan pengujian regresi, korelasi, determinasi dan uji hipotesis. Hasil penelitian ini variabel Modal kerja diperoleh nilai rata-rata sebesar 3303 milyar. Variabel Return On Asset diperoleh nilai rata-rata 5,75\%\%. Modal kerja tidak berpengaruh signifikan terhadap Return On Asset dengan nilai persamaan regresi $\mathrm{Y}=8,749$ 0,001X, dan nilai koefisien korelasi -0,481 atau memiliki tingkat hubungan yang negatif sedang dengan nilai determinasi 23,2\%. Uji hipotesis diperoleh signifikansi 0,159>0,05.
\end{abstract}

\section{Kata Kunci: Modal Kerja, Profitabilitas.}

\begin{abstract}
This study aims to determine the effect of working capital on profitability at PT. Japfa Comfeed Indonesia. Tbk. The method used is explanatory research. The analysis technique uses statistical analysis with regression testing, correlation, determination and hypothesis testing. The results of this study, the working capital variable obtained an average value of 3303 billion. The return on asset variable obtained an average value of $5.75 \% \%$. Working capital has no significant effect on Return On Assets with the regression equation value $Y=$ $8.749-0.001 X$, and the correlation coefficient value is -0.481 or has a moderate negative relationship level with a determination value of 23.2\%. Hypothesis testing obtained a significance of $0.159>0.05$.
\end{abstract}

Keywords: Working Capital, Profitability. 


\section{PENDAHULUAN}

\section{A. Latar Belakang Masalah}

Kegiatan perusahaan dalam mencapai suatu tujuannya harus dikelola dengan baik, pengelola keuangan yang baik akan memberikan pencapaian kinerja yang maksimal. Upaya untuk melaukan pengelolaan keuangan yang baik, yaitu dengan pengelolaan aset perusahaan secara efisien dan efektif. Penanggung jawab pengelola keuangan, atau dalam hal aset perusahaan yang meliputi aset lancar adalah manager keuangan. Aktiva lancar perusahaan merupakan aktiva yang harus diperhatikan dengan baik, karena memiliki perputaran yang lebih cepat dibandingkan dengan aktiva tetap.

Pengelolaan modal kerja merupakan hal yang sangat penting dalam perusahaan, karena berpengaruh dalam pengambilan keputusan mengenai jumlah dan komposisi aktiva lancar dan bagaimana membiayai aktiva ini. Perusahaan yang tidak dapat memperhitungkan tingkat modal kerja yang memuaskan, maka perusahaan akan mengalami insolvency (tidak mampu memenuhi kewajiban-kewajiban tunai yang telah jatuh tempo) yang memungkin kan perusahaan akan dilikuidasi. Aktiva lancar lebih besar dari pada hutang lancar akan membuat manajemen modal kerja yang positif, sehingga menggambarkan adanya tingkat keamanan (margin safety) yang memuaskan. Sementara itu jika perusahaan menetapkan modal kerja berlebih akan menyebabkan perusahaan overlikuid sehingga menimbulkan dana menganggur yang mengakibatkan inefisiensi perusahaan, dan membuang kesempatan memperoleh laba.

Menurut Kasmir (2011) dalam Bagus Mangdahita Sariyana, Fridayana Yudiatmaja dan I Wayan Suwendra (2016) modal kerja dapat diartikan sebagai investasi yang ditanamkan dalam aktiva lancar atau jangka pendek, seperti kas bank, surat-surat berharga , piutang, persediaan, dan aktiva lancar lainnya. Modal kerja ini akan berputar setiap periodenya didalam perusahaan. Semakin pendek periode perputaran modal kerja akan lebih efisien dan dapat meningkatkan profitabilitas. Sebaliknya, semakin lama periode perputaran modal kerja maka profitabilitas perusahaan akan semakin menurun. Profitabilitas perusahaan juga sangat berhubungan dengan pengelolaan aktiva yang dimiliki oleh perusahaan, sehingga hal ini akan berkaitan dengan likuiditas perusahan.

Dengan terus meningkatknya permintaan konsumen terhadap produk makanan dan minuman maka setiap perusahaan harus memiliki kemampuan manajemen yang baik agar perusahaan yang dijalankan mampu bersaing dengan perusahaan-perusahaan yang ada. Setiap perusahaan pastinya memiliki strategi demi meningkatkan penjualannya, dan strategi bagaimana untuk mempertahankan dan meningkatkan penjualan produk setiap tahunnya sehingga produk yang dihasilkan mampu memikat minat konsumen guna meningkatkan penjualan produk yang dihasilkan secara terus menerus, dengan begitu maka profitabilitas perusahaan juga akan meningkat. Dengan meningkatnya profitabilitas dapat menggambarkan keberhasilan manajemen dalam menjalankan suatu perusahaan.

Berikut ini merupakan ringkasan data keuangan yang berhubungan dengan variabel yang digunakan dalam penelitian ini, yaitu: Modal kerja, Likuiditas dan Profitabilitas.

Tabel 1. Modal kerja dan Return on Asset PT. Japfa Comfeed Indonesia, Tbk Periode 2010-2019

\begin{tabular}{|c|c|c|}
\hline Tahun & Modal Kerja (Dalam Milyar) & Return on Asset (\%) \\
\hline 2010 & 1572.707 & 5.28 \\
\hline 2011 & 2169.661 & 13.42 \\
\hline 2012 & 935.769 & 5.11 \\
\hline 2013 & 786.237 & 7.69 \\
\hline 2014 & 2905.609 & 9.8 \\
\hline 2015 & 4643.121 & 4.29 \\
\hline
\end{tabular}




\begin{tabular}{|c|c|c|}
\hline 2016 & 3792.87 & 2.49 \\
\hline 2017 & 4251.484 & 3.06 \\
\hline 2018 & 5561.954 & 1.13 \\
\hline 2019 & 6419.685 & 5.25 \\
\hline
\end{tabular}

Sumber: PT. Japfa Comfeed Indonesia, tbk

Berdasarkan tabel 1. diatas selama 10 tahun dari tahun 2008 sampai tahun 2017, pertumbuhan modal kerja yang dimiliki PT. Japfa Comfeed Indonesia, tbk mengalami pekembangan yang fluktuatif nominal tertinggi diperoleh pada tahun terakhir yaitu 2019 sebesar Rp. 6.419.685 dan pencapaian terendah terjadi pada tahun 2013 sebesar Rp. 786.237.

Kemudian sepanjang tahun 2010 sampai 2019 pertumbuhan return on asset PT. Japfa Comfeed Indonesia, Tbk mengalami perkembangan yang berfluktuatif terlihat dari tingkat presentase ratio. Presentase tertinggi terjadi pada tahun 2011 mencapai 13,42\% d

Tujuan akhir yang ingin dicapai suatu perusahaan yang terpenting adalah memperoleh laba atau keuntungan yang maksimal, di samping hal-hal lainnya. Untuk mengukur tingkat keuntungan suatu perusahaan, digunakan rasio keuntungan atau rasio profitabilitas yang dikenal juga dengan nama rasio profitabilitas.

Pengertian profitabilitas menurut Agus Sartono (2010) profitabilitas adalah kemampuan perusahaan memperoleh laba dalam hubungannya dengan penjualan, total aktiva , maupun modal sendiri. Dapat disimpulkan bahwa profitabilitas adalah suatu takaran yang digunakan untuk mengukur kemampuan perusahaan dalam mengasilkan keuntungan pada beberapa periode tertentu. Profitabilitas juga merupakan faktor penting dalam menilai tingkat kesehatan perusahaan. Profitabilitas mencerminkan kemampuan perusahaan dalam menghasilkan laba secara efektif dan efisien. Perkembangan laba yang diperoleh perusahaan dapat diketahui melalui laporan keuangan perusahaan. Ada beberapa alat ukur yang dipergunakan untuk mengukur tingkat profitabilitas, antara lain: Return On Asset (ROA) dan Return On Equity (ROE). Dan didalam penelitian ini profitabilitas akan diukur dengan menggunakan Return On Asset (ROA).

Dalam hal ini dapat dilihat bahwa terjadi ketidaksamaan anatara modal kerja dengan profitabilitas. Begitupun dengan tingkat likuiditas yang tidak sejalan dengan perkembangan profitabilitas. Kenyataan tersebut menyimpang dari teori yang ada, dimana secara teori apabila perusahaan memiliki tigkat modal kerja yang tinggi maka tingkat profitabilitasnya juga akan tinggi. Begitupun hubungannnya dengan tingkat likuiditas yang diperoleh perusahaan uang memiliki pengaruh terhadap tingkat profitabilitas. Oleh karena itu, perlu penelitian untuk mengetahui pemgaruh penggunaan modal kerja dalam memperoleh laba serta tingkat likuiditas yang diperoleh dan ditinjau dari tingkat profitabilitas yang dicapai perusahaannya.

\section{B. Rumusan Masalah}

1. Bagaimana Modal kerja pada pada PT. Japfa Comfeed Indonesia. Tbk ?.

2. Bagaimana Return On Asset pada PT. Japfa Comfeed Indonesia. Tbk ?.

3. Adakah pengaruh antara Modal kerja terhadap Return On Asset pada PT. Japfa Comfeed Indonesia. Tbk?.

\section{Tujuan Penelitian}

1. Untuk mengetahui kondisi Modal kerja pada PT. Japfa Comfeed Indonesia. Tbk.

2. Untuk mengetahui kondisi Return On Asset pada PT. Japfa Comfeed Indonesia. Tbk.

3. Untuk mengetahui pengaruh antara Modal kerja terhadap Return On Asset pada PT. Japfa Comfeed Indonesia. Tbk. 


\section{METODE PENELITIAN}

\section{Populasi}

Populasi dalam penelitian ini laporan keuangan PT. Japfa Comfeed Indonesia. Tbk selama 10 tahun

2. Sampel

Teknik pengambilan sampling dalam penelitian ini adalah samplel jenuh, dimana semua anggota populasi dijadikan sebagai sampel. Dengan demikian sampel dalam penelitian ini laporan keuangan PT. Japfa Comfeed Indonesia. Tbk selama 10 tahun.

\section{Jenis Penelitian}

Jenis penelitian yang dipakai adalah asosiatif, dimana tujuannya adalah untuk mengetahui mencari keterhubungan antara variabel independen terhadap variabel dependennya

\section{Metode Analisis Data}

Dalam menganalisis data digunakan uji validitas, uji reliabilitas, analisis regresi linier sederhana, koefisien korelasi, koefisien determinasi dan uji hipotesis.

\section{HASIL PENELITIAN DAN PEMBAHASAN}

\section{Analisis Deskriptif}

Pada pengujian ini digunakan untuk mengetahui skor minimum dan maksimum skor tertinggi, ratting score dan standar deviasi dari masing-masing variabel. Adapun hasilnya sebagai berikut:

Tabel 1. Hasil Analisis Descriptive Statistics

\section{Descriptive Statistics}

\begin{tabular}{|l|r|r|r|r|r} 
& N & Minimum & Maximum & \multicolumn{1}{c}{ Mean } & \multicolumn{1}{c}{ Std. Deviation } \\
\hline Modal kerja (X1) & 10 & 786 & 6420 & 3303.91 & 1947.257 \\
\hline Return On Asset (Y) & 10 & 1.13 & 13.42 & 5.7520 & 3.66993 \\
\hline Valid N (listwise) & 10 & & & & \\
\hline
\end{tabular}

Modal kerja diperoleh nilai minimum sebesar 786 dan nilai maximum 6420 dengan rata-rata sebesar 3303,91 dengan standar deviasi 1947.257.

Return On Asset diperoleh nilai minimum sebesar 1,13 dan nilai maximum 13,42 dengan rata-rata sebesar 5,752 dengan standar deviasi 3,669.

\section{Analisis Verifikatif.}

Pada analisis ini dimaksudkan untuk mengetahui pengaruh variabel independen terhadap variabel dependen. Adapun hasil pengujian sebagai berikut:

\section{a. Analisis Regresi Linier Sederhana}

Uji regresi ini dimaksudkan untuk mengetahui perubahan variabel dependen jika variabel independen mengalami perubahan. Adapun hasil pengujiannya sebagai berikut:

\begin{tabular}{|c|c|c|c|c|c|}
\hline \multirow[b]{2}{*}{ Model } & $\begin{array}{r}\text { C } \\
\text { Unsta } \\
\text { Coe }\end{array}$ & $\begin{array}{l}\text { efficients } \\
\text { dardized } \\
\text { ficients }\end{array}$ & \multirow[t]{2}{*}{$\begin{array}{l}\text { Standardized } \\
\text { Coefficients }\end{array}$} & \multirow[b]{2}{*}{$t$} & \multirow[b]{2}{*}{ Sig. } \\
\hline & B & Std. Error & & & \\
\hline 1 (Constant) & 8.749 & 2.211 & & 3.957 & .004 \\
\hline Modal kerja $(\mathrm{X})$ & -.001 & .001 & -.481 & -1.553 & .159 \\
\hline
\end{tabular}

Berdasarkan hasil pengujian pada tabel di atas, diperoleh persamaan regresi $\mathrm{Y}$ $=8,749-0,001 X$. Dari persamaan tersebut dijelaskan sebagai berikut:

1) Konstanta sebesar 8,749 diartikan jika Modal kerja tidak ada, maka telah terdapat nilai Return On Asset sebesar 8,749 point. 
2) Koefisien regresi Modal kerja sebesar -0,001, angka ini negatif artinya setiap ada penurunan Modal kerja sebesar -0,001 point maka Return On Asset juga akan mengalami penurunan sebesar -0,001 point.

\section{b. Analisis Koefisien Korelasi}

Analisis koefisien korelasi dimaksudkan untuk mengetahui tingkt kekuatan hubungan dari variabel independen terhadap variabel dependen baik secara parsial maupun simultan. Adapun hasil pengujian sebagai berikut:

Tabel 3. Hasil Pengujian Koefisien Korelasi Modal kerja Terhadap Return On Asset.

\section{Correlations $^{\mathrm{b}}$}

\begin{tabular}{ll|rr} 
& & $\begin{array}{c}\text { Modal kerja } \\
(\mathrm{X} 1)\end{array}$ & $\begin{array}{r}\text { Return On Asset } \\
(\mathrm{Y})\end{array}$ \\
\hline Modal kerja $(\mathrm{X} 1)$ & Pearson Correlation & 1 & -.481 \\
\cline { 2 - 4 } & Sig. (2-tailed) & & .159 \\
\hline Return On Asset $(\mathrm{Y})$ & Pearson Correlation & -.481 & 1 \\
\cline { 2 - 4 } & Sig. (2-tailed) & .159 & \\
\hline
\end{tabular}

Berdasarkan hasil pengujian diperoleh nilai korelasi sebesar $-0,481$ artinya Modal kerja memiliki hubungan yang negatif sedang terhadap Return On Asset.

\section{c. Analisis Koefisien Determinasi}

Analisis koefisien determinasi dimaksudkan untuk mengetahui besarnya persentase pengaruh dari variabel independen terhadap variabel dependen. Adapun hasil pengujian sebagai berikut:

Tabel 4. Hasil Pengujian Koefisien Determinasi Modal kerja Terhadap Return On Asset. Model Summary

\begin{tabular}{lrr|rr|r} 
Model & $\mathrm{R}$ & R Square & $\begin{array}{c}\text { Adjusted R } \\
\text { Square }\end{array}$ & $\begin{array}{c}\text { Std. Error of the } \\
\text { Estimate }\end{array}$ \\
\hline 1 & & $.481^{\mathrm{a}}$ & .232 & .136 & 3.41201 \\
\hline
\end{tabular}

Berdasarkan hasil pengujian diperoleh nilai determinasi sebesar 0,232 artinya Modal kerja memiliki kontribusi pengaruh sebesar 23,2\% terhadap Return On Asset.

\section{d. Uji Hipotesis}

Pengujian hipotesis dengan uji $\mathrm{t}$ digunakan untuk mengetahui hipotesis mana yang diterima.

Rumusan hipotesis: Terdapat pengaruh yang signifikan antara Modal kerja terhadap Return On Asset.

Tabel 5. Hasil Uji Hipotesis Modal kerja Terhadap Return On Asset.

\section{Coefficients $^{a}$}

\begin{tabular}{|c|c|c|c|c|c|c|}
\hline \multirow{2}{*}{\multicolumn{2}{|c|}{ Model }} & \multicolumn{2}{|c|}{$\begin{array}{c}\text { Unstandardized } \\
\text { Coefficients }\end{array}$} & \multirow{2}{*}{$\begin{array}{c}\text { Standardized } \\
\text { Coefficients } \\
\text { Beta } \\
\end{array}$} & \multirow[b]{2}{*}{$\mathrm{t}$} & \multirow[b]{2}{*}{ Sig. } \\
\hline & & $\mathrm{B}$ & Std. Error & & & \\
\hline & (Constant) & 8.749 & 2.211 & & 3.957 & .004 \\
\hline & Modal kerja $(\mathrm{X})$ & -.001 & .001 & -.481 & -1.553 & .159 \\
\hline
\end{tabular}

Berdasarkan hasil pengujian pada tabel di atas, diperoleh nilai t hitung $<\mathrm{t}$ tabel atau $(-1,553<2,306)$, dengan demikian hipotesis yang diajukan bahwa tidak terdapat pengaruh yang signifikan atara Modal kerja terhadap Return On Asset diterima.

\section{PEMBAHASAN HASIL PENELITIAN}

1. Kondisi Jawaban Responden Variabel Modal kerja

Berdasarkan data empiris dan analisis data, variabel Modal kerja diperoleh nilai rata-rata 
per tahun sebesar 3.303 milyar.

2. Kondisi Jawaban Responden Variabel Return On Asset

Berdasarkan data empiris dan analisis data, variabel Return On Asset diperoleh nilai ratarata per tahun sebesar $5,75 \%$.

3. Pengaruh Modal kerja Terhadap Return On Asset

Modal kerja berpengaruh signifikan terhadap Return On Asset dengan persamaan regresi $\mathrm{Y}=8,749+-0,001 \mathrm{X}$, nilai korelasi sebesar $-0,481$ atau memiliki hubungan yang kuat dengan kontribusi pengaruh sebesar $23,2 \%$. Pengujian hipotesis diperoleh nilai $\mathrm{t}$ hitung $>\mathrm{t}$ tabel atau $(-1,553>2,306)$. Dengan demikian hipotesis yang diajukan bahwa terdapat berpengaruh signifikan antara Modal kerja terhadap Return On Asset diterima.

\section{V.PENUTUP}

\section{Kesimpulan}

a. Variabel Modal kerja diperoleh nilai rata-rata per tahunnya sebesar 3303 milyar.

b. Variabel Return On Asset diperoleh nilai rata-rata per tahunnya sebesar 13,42\%.

c. Modal kerja berpengaruh signifikan terhadap Return On Asset dengan persamaan regresi $\mathrm{Y}=8,749-0,001 \mathrm{X}$, nilai korelasi sebesar $-0,481$ atau kuat dan kontribusi pengaruh sebesar $23,2 \%$ sedangkan sisanya sebesar $76,8 \%$ dipengaruhi faktor lain. Uji hipotesis diperoleh nilai $t$ hitung $<\mathrm{t}$ tabel atau $(-1,553<2,306)$.

\section{Saran}

a. Perusahaan harus mencermati kondisi keuangan agar kondisi perusahaan memiliki tingkat resiko investasi yang perlu dicermati sehingga berpengaruh terhadap harga saham perusahaan.

b. Agar tidak terjasi penurunan return on asset (ROA) perusahaan harus mencermati potensi pertumbuhan harga saham yang cenderung dinamis membuat investor menghadapi resiko investasi terhadap perusahaan bila tidak di cermati.

c. Investor selalu mengharapkan harga saham yang naik agar mendapat keuntungan saham yang lebih besar

\section{DAFTAR PUSTAKA}

Agus Harjito \& Martono, (2010) "Manajemen Keuangan” Yogyakarta: Penerbit Ekonisia. Algifari. (2015). “Analisis Regresi untuk Bisnis dan Ekonomi”. Yogyakarta: BPFE.

Arikunto, Suharsimi (2014). "Prosedur Penelitian Suatu Pendekatan Praktek". Jakarta: Rineka Cipta.

Bambang Riyanto, (2011). "Dasar-dasar Pembelanjaan Perusahaan”. Edisi ke empat, BPFE Yogyakarta.

Fahmi, Irham (2012), "Pengantar Manajemen Keuangan” Cetakan pertama. Bandung: Penerbit Alfabeta.

Imam Ghozali (2017). “Aplikasi Analisis Multivariate Dengan Program SPSS”. Edisi Kelima. Semarang: Badan Penerbit Undip.

Istijanto (2014) “Riset Sumber Daya Manusia”. Jakarta: PT. Gramedia Pustaka

Jasmani, J. (2018). Pengaruh Kinerja Keuangan Terhadap Harga Saham (Analisis Pada Perusahaan Property dan Real Estate Yang Go Public di Bursa Efek Indonesia. Jurnal Akuntansi Indonesia, 12(2).

Jasmani, J. (2019). The Effect of Liquidity and Working Capital Turnover on Profitability at PT. Sumber Cipta Multiniaga, South Jakarta. PINISI Discretion Review, 3(1), 2938.

Jasmani, Jasmani, and Denok Sunarsi. "The Influence of Product Mix, Promotion Mix and 
Brand Image on Consumer Purchasing Decisions of Sari Roti Products in South Tangerang." PINISI Discretion Review 1.1 (2020): 165-174.

Kasmir (2010), "Analisis Laporan keuangan”, penerbit raja grafindo persada, Jakarta

Kasmir. (2012) "Pengantar Manajemen Keuangan", Edisi Pertama, Cetakan kedua, Jakarta: Prenada Media.

Kharis, Ismu Fadli (2011). "Studi Mengenai Impulse Buying dalam Penjualan Online”. Semarang : Skripsi Universitas Diponegoro

Martono dan Agus Harjito, (2011). "Manajemen Keuangan”, Jakarta: Penerbit Ekonisia.. Munawir (2010), "Analisis Laporan Keuangan”, Edisi Ke Empat, Penerbit Liberty, Yogyakarta.

Nuryani,Y. D Sunarsi. (2020). The Effect of Current Ratio and Debt to Equity Ratio on Deviding Growth. JASa (Jurnal Akuntansi, Audit dan Sistem Informasi Akuntansi) 4 (2), 304-312.

Santoso, Singgih (2015). “Menguasai Statistik Multivariat”. Jakarta: PT Elex Media Komputindo.

Sartono, "Manajemen Keuangan Aplikasi Dan Teori”, Edisi Keempat, BPFE, Yogyakarta, 2008.

Sawir, (2003). "Analisis Kinerja Keuangan dan Perencanaan Keuangan Perusahaan", Cetakan ketiga, Jakarta: Penerbit PT. Gramedia Pustaka Utama.

Sugiyarso, G. dan F. Winarni, "Manajemen Keuangan (Pemahaman Laporan Keuangan, Pengelolaan Aktiva, Kewajiban dan Modal serta Pengukuran

Sugiyono (2017), "Metode Penelitian Administrasi : dilengkapi dengan Metode $R \&$ D”. Bandung: Alfabeta.

Sunarsi, D., \& Baharuddin, A. (2019). The Effect of Service Quality and Price Accuracy on Consumer Confidence and Implications for Sales Increase. PINISI Discretion Review, 3(2), 101-110.

Sunarsi, D., \& Kusjono, G. (2019). Pengaruh Lingkungan Kerja Non Fisik, Konflik Dan Turn Over Intention Terhadap Produktivitas Kerja Karyawan Pada CV. Usaha Mandiri Jakarta Selatan. Jurnal Ekonomi Efektif, 1(3).

Susanti, N., Latifa, I., \& Sunarsi, D. (2020). The Effects of Profitability, Leverage, and Liquidity on Financial Distress on Retail Companies Listed on Indonesian Stock Exchange. Jurnal Ilmiah Ilmu Administrasi Publik, 10(1), 45-52. 